\title{
The caudate nucleus and active avoidance: A comment on the report of Winocur \& Mills ${ }^{1}$
}

ROBERT J. KIRKBY, Neurophysiology Laboratory, Psychiatric Research Unit, Rozelle, New South Wales 2039, Australia

Recently, Winocur \& Mills (1969) published a report on the effects of caudate-nucleus lesions on avoidance behavior in the rat. They found that in passive-avoidance learning rats with caudate lesions were impaired in inhibiting a well trained response but not in inhibiting a relatively spontaneous untrained response. This finding was in accord with the earlier report of Kirkby \& Kimble (1968). The observation of Winocur and Mills, that caudate-nucleus lesions did not distupt active avoidance, was not in agreement with the findings of Kirkby and Kimble, nor was it in agreement with several other reports that Winocur and Mills did not cite (for example, Turner, 1954; Romanovskaya, 1957; Gomez et al, 1958; Thompson \& Mettler, 1963; Konorski, 1967; Kirkby, 1968). The aim of the present note is to briefly review some of these reports.

Monkeys with lesions of the caudate nucleus were impaired in learning a "shuttlebox" type of problem. In this study (Turner, 1954), failure to avoid the end of the cage identified by an auditory signal was punished by delivery of a negative reinforcement.

Thompson (1959) reported that cats with lesions of the dorsofrontal cortex and underlying caudate nucleus were markedly deficient in relearning a two-way shuttlebox avoidance task, learned after frontal decortication but prior to caudectomy. Avoidance impairments were correlated with the magnitude of caudate damage; one cat with extensive caudate injury failed to avoid in more than 1,000 trials. Similar deficits were reported in caudate-lesioned cats in simple one-way avoidance learning (Thompson \& Mettler, 1963) and in avoidance tasks requiring leg flexion, face turning (Thompson \& Mettler, 1963), or lever-pressing responses (Konorski, 1967, p. 480).

Romanovskaya (1957) has reported that dogs with bilateral destruction of caudate tissue were impaired in performing an avoidance task requiring a paw lift to avoid shock. These deficits were apparent in tests carried out as late as 12 weeks after operation.

Impairments in the learning of both one-way (Kirkby \& Kimble, 1968; Kirkby, 1969) and two-way (Green et al, 1967) active-avoidance learning has been reported in caudate-lesioned rats. In the Kirkby and Kimble study, impairments were found up to 90 days after operation. No later tests were carried out.

Stimulation of the caudate nucleus has been found to disrupt the performance of active-avoidance responses (Stevens et al, 1961). Cats were trained to avoid an electric shock by jumping over a low barrier or by escaping through a doot at the sound of a buzzer. Electrical or chemical stimulation of the caudate by injection of carbachol severely disrupted this response for periods ranging from 4 to $24 \mathrm{~h}$. During stimulation trials, the cats showed marked fear reactions to the onset of the buzzer and the electric shock. Similarly, although caudate-iesioned animals are impaired in active-avoidance tasks, they still show affective responses associated with the perception of pain. Kirkby \& Kimble (1968) described their caudate-lesioned rats as showing "consistent fear responses, such as urination, defecation, and a strong resistance to being placed in the shock chamber [p. 244]." Similar observations have been reported by others (Gomez et al, 1958; Thompson, 1959; Konorski, 1967, p. 480).

In conclusion, although some investigations have indicated that lesions of the caudate have no effect on active-avoidance behavior (Fox et al, 1964; Albert \& Bignami, 1968; Winocur \& Mills, 1969), the majority of reports have shown clearly that active avoidance is disrupted following lesions of the caudate nucleus (Turner, 1954; Romanovskaya, 1957; Gomez et al, 1958; Thompson, 1959; Thompson \& Mettier, 1963; Konorski, 1967; Green et al, 1967; Kirkby \& Kimble, 1968; Kirkby, 1968, 1969).

\section{REFERENCES}

ALBERT, M., \& BIGNAMI, G. Effects of frontal, median cortical and caudate lesions on two-way avoidance learning by rats. Physiology \& Behavior, 1968, 3, 141-147.

FOX, S. S., KIMBLE, D. P., \& LICKEY, M. E. Comparison of caudate nucleus and septal-area lesions on two types of avoidance behavior. Journal of Comparative \& Physiological Psychology, 1964, 58, 380-386.

GOMEZ, J. A., THOMPSON, R. L., \& METTLER, F. A. Effect of striatal damage on conditioned and unleamed behavior. Transactions of the American Neurological Association, 1958, 83, 88-91.

GREEN, R. H., BEATTY, W. W., \& SCHWARTZBAUM, J. S. Comparative effects of septo-hippocampal and caudate lesions on avoidance behavior in sats. Journal of Comparative \& Physiological Psychology. $1967,64,444-452$.

KIRKBY, R. J. The caudate nucleus and CNS functions. Australian Joumal of Experimental Biology \& Medical Science, 1968, 46, 11.

KIRKBY, R. J. Caudate nucleus lesions and perseverative behavior. Physiology \& Behavior, $1969,4,451-454$.

KIRKBY, R. J., \& KIMBLE, D. P. Avoidance and escape behavior following striatal lesions in the rat. Experimental Neurology, 1968, 20. 215-227.

KONORSKI, J. Integrative activity of the brain. The University of Chicago, Chicago, 1967.

ROMANOVSKAYA, E. A. Certain consequences of destroying the caudate nuclei in rabbits and dogs. Bulletin of Experimental Biology \& Medicine, 1957, 44, 1066-1069.

STEVENS, J. R., KIM, C. \& McLEAN, P. D. Stimulation of caudate nucleus. Archives of Neurology, 1961, 4, 47-54.

THOMPSON, R. L. Effects of lesions in the caudate nuclei and dorsofrontal cortex on conditioned avoidance behavior in cats. Journal of Comparative \& Physiological Psychology, 1959, 52, 650-659.

THOMPSON, R. L. \& METTLER, F. A. Permanent learning deficit associated with lesions in the caudate nuclei. American Joumal of Mental Deficiency, 1963, 67, 526-535.

TURNER, E. A. Cerebral control of respiration. Brain, 1954, 77, 448-486.

WINOCUR, G., \& MILLS, J. A. Effects of caudate lesions on avoidance behavior in rats. Journal of Comparative \& Physiological Psychology, 1969, 68, 552-557.

$$
\text { NOTE }
$$

1. This research was supported by funds from the New South Wales Department of Public Health. 